\title{
The Roles of Training in Language Teaching Practices: An Analysis of Wittgenstein's Consideration
}

\author{
Sato Kunimasa (Corresponding author) \\ Dept. of Philosophy, Faculty of Humanities and Sciences, Nihon University, \\ Dept. of Philosophy, University of Miami
}

Akitsu 5-7-7, Narashino-shi, Chiba 275-0025, Japan

Tel: 1-305-613-3275 E-mail: miamikunickham@gmail.com

Received: May 8, 2014 Accepted: May 23, 2014 Published: July 4, 2014

doi:10.5296/jet.v1i2.5917 URL: http://dx.doi.org/10.5296/jet.v1i2.5917

\begin{abstract}
This paper reveals distinct roles of training in language teaching practices by critically examining Wittgenstein's arguments regarding ostensive definition and ostensive teaching. Specifically, I will clarify three points. First, based on relevant literature, I will show that ostensive definition involves employing words - including demonstratives, such as 'this', as well as ostensive gestures - and that, in order for this teaching practice to make sense to children, they must have a prior understanding of demonstratives and ostensive gestures. Second, I will argue that training as considered by Wittgenstein plays at least two distinct roles, which will be called 'training of reaction' and 'training of repetition'. Finally, I will claim that ostensive teaching based on training enables children to react to words and ostensive gestures without reflection and to treat new things of the same sort as samples of the particular items taught. My findings open up further research to explore various roles that training plays in educational practices, including training and drills in the classroom.
\end{abstract}

Keywords: language teaching practices, things seen as samples, training of reaction, training of repetition, Wittgenstein

\section{Introduction}

When teaching a first language, parents or educators often point to things, uttering words so that children can learn to use those words properly. From the so-called 'transition period' ${ }^{1}$ to the late period, Wittgenstein is concerned with teaching a first language with ostensive

\footnotetext{
1 The period between 1929 and 1933 is called the 'transition period' because, in this period, Wittgenstein recommenced his philosophical investigations and moved toward his later thought (Glock, 1996, p. 21).
} 
gestures, including what he calls 'ostensive definition' and 'ostensive teaching'. In his transition period, Wittgenstein considered that words and things are connected by language teaching practices and focused his attention on the following problem of the connection between words and things:

The connection of word and thing that is established by teaching a language. What sort of connection is this, of what kind is it? What kind of connections are there? $(\mathrm{TS} 213,173)^{2}$ $(\text { cf. } P G, 56)^{3}$

After abandoning the view that the relationship between words and things is dichotomistic, that is, that words are a component of language and things are outside of language, with 'ostensive definition' connecting words and things (Glock, 1996, pp. 20-1), Wittgenstein introduced a concept of 'language games'. These language games stand for the whole, consisting of both language and the actions into which it is woven (e.g., PI, 7). ${ }^{4}$ Given that language games encompass 'primitive language' or language learners' initial form of languages when they learn to talk (PI, 5; 7), how words and things are used properly is taught in 'ostensive teaching' based on training as a part of language games (BB, 77; PI, 6).

This paper reveals distinct roles of training in language teaching practices by critically examining Wittgenstein's arguments regarding ostensive definition and ostensive teaching. Specifically, given the literature on teaching and learning in Wittgenstein's philosophy, ${ }^{5}$ I will make clear two points. First, after articulating the characteristics of ostensive definition and ostensive teaching, I will explicate their differences by paying close attention to Wittgenstein's views in both the transition and later period. Although much literature has focused only on ostensive definition and ostensive teaching in the later Wittgenstein (e.g., Luntley, 2007; 2008; Williams, 1999, 2010), Wittgenstein examines the idea of ostensive definition as a primary sign in the transition period and presents the concept of ostensive teaching in the later period by criticizing ostensive definition. Second, I will argue that ostensive teaching includes at least two distinct roles of training, which I call 'training of

2 The following standard abbreviations of titles to Wittgenstein's works are used throughout and, when I quote Wittgenstein's texts, I maintain the original passages:

PG: Philosophical Grammar (Oxford: Blackwell, 1974)

TS213: The Big Type Script TS213 (Oxford: Blackwell, 2005)

BB: The Blue and Brown Books (Oxford: Blackwell, 1958)

PI: Philosophical Investigations, 3rd ed. (Oxford: Blackwell, 2001)

RFM: Remarks on the Foundations of Mathematics, 3rd ed. (Oxford: Blackwell, 1978)

${ }^{3}$ I cite both PG and TS213 as a reference when the ideas expressed are relevant or similar to each other.

${ }^{4}$ Language games were first explained as, "the forms of language with which a child begins to make use of words' (BB, 17).

${ }^{5}$ See Burbules and Peters (2001) for obtaining the general overview of the relationship between education and Wittgenstein's philosophy. Concepts such as 'teaching' and 'learning' in Wittgenstein's argument are said to be of great importance for understanding his entire philosophy (Glock, 1996, p.194; Williams, 1999, p.188). 
reaction' and 'training of repetition' respectively. Considering the growing attention to the concept of training, such as Stickney (2008), this clairfication will help underscore the significance of training in language teaching practices.

The following argument consists of two parts. In section 2, in order to clarify the relationship between words and things in ostensive definition as a primary sign, I will explain the three characteristics of ostensive definition and delineate Wittgenstein's criticisms of the ostensive definition. In section 3, I will expound on the reason Wittgenstein argues that ostensive teaching is not explanation but training, by clarifying two distinct roles of training, that is, the training of reaction and the training of repetition in ostensive teaching. I will then demonstrate the difference between ostensive teaching and ostensive definition, which may enable us to appreciate distinct roles of training in educational practices.

\section{Ostensive Definition as a Primary Sign}

In the writings of Wittgenstein, there are usually two parts: one part in which he presents a view that is opposed to his, and another part in which he presents his criticism of that view. The former part is dealt with in section 2.1 while the latter part is discussed in section 2.2.

\subsection{Characteristics of Ostensive Definition}

I shall begin by outlining the idea of ostensive definition, which Wittgenstein considers in the transition period:

Does our language consist of primary signs (ostensive gestures) and secondary signs (words)? One is inclined to ask, whether it isn't the case that our language has to have primary signs while it could get by without the secondary ones. (PG, 46) (cf. TS213, 46) (emphasis original)

A red colour chip is a primary sign for red, the word a secondary one, because pointing to a red chip, etc., explains the meaning of the word 'red', but saying that 'red' is the equivalent of 'rouge' doesn't. (TS213, 45) (cf. PG, 47)

Wittgenstein introduces here the ostensive definition, called a 'primary sign', by contrasting it with the 'secondary sign'. Ostensive definition largely consists of ostensive gestures, such as pointing, and the things that are pointed to. On the other hand, the secondary sign comprises the relation of translation into words, and words in another language, such as 'rouge', that correspond to words in the original language, such as 'red'. In contrast to the secondary sign, ostensive definition as a primary sign is supposed to explain the meaning of words. $^{6}$

Why is ostensive definition regarded as explaining the meaning of words? The reason is that

\footnotetext{
${ }^{6}$ Glock (1996, p. 274) states, 'An ostensive definition is an explanation of the meaning of a word as in 'This is an elephant' or 'That colour is called 'red".
} 
ostensive definition plays the role of connecting language with reality, specifically between words and things in the present context:

Rules of grammar that establish a 'connection between language and reality', and those that don't. 'I call this colour 'red"' is an example of the first kind, for instance. (TS213, 54) (cf. PG 46, 55)

The connection of words with things is, it is supposed, made by ostensive definition, which belongs to 'grammar' (PG, 55; TS213, 43) (cf. Glock, 1996, p. 276). This is the reason ostensive definition, belonging to grammar, offers the explanation of words.

Behind this view of ostensive definition is an idea of two distinct stages of language learning: the first stage is grammar and the second is applications of language (TS213, 42). I use the word 'stage' here because the distinction between grammar and applications of language stands for the process of learning a language as well as a conceptual difference. Grammar is the stage at which the connection between words and things is made by ostensive definition, and the meaning of words is completely determined ( $P G, 45)$, whereas the application of language is the stage in which sentences, such as 'Give me this cabbage', are used.

According to this view of language learning, ostensive gestures are not a part of gestures in various applications of language (Harris, 2002, pp. 127-8). What belongs to grammar, encompassing ostensive definition, is everything that is required for comparing language and reality, and this is the requirement for understanding (PG, 45; TS213, 43).

Furthermore, the ostensive definition characterized above must be 'unambiguous', that is, free from being misinterpreted (PG, 48; TS213, 54). Thus, ostensive definition as a primary sign is regarded as a preparatory stage for applications of language:

The interpretation of written and oral signs by ostensive explanations is not an application of language, but a part of grammar. The interpretation still takes place in a general realm, as a preparation for any application. (TS213, 42; 43)

Let us summarize the three characteristics with regard to ostensive definition:

(2.1.1) Ostensive definition as a primary sign encompasses ostensive gestures, such as pointing, and things that are pointed to.

(2.1.2) Ostensive definition connects words and things.

(2.1.3) Ostensive definition does not allow for multiple interpretations, encompassing misinterpretation. 


\subsection{Two Criticisms of Ostensive Definition}

In this section, I will articulate Wittgenstein's two criticisms of the characteristics of ostensive definition as language learning. The first criticism of characteristic (2.1.3) of ostensive definition in the previous section is that ostensive definition allows for multiple interpretations. The second criticism of characteristic (2.1.2) is that ostensive definition is merely one application of language, particularly after the language game of asking names is set.

Let us clarify the first criticism of ostensive definition as a primary sign. ${ }^{7}$ Remember that the connection between words and things is made by ostensive definition in grammar, and it does not allow for multiple interpretations. Concerning these suppositions, Wittgenstein asked:

Are the signs one wants to call 'primary' incapable of being misinterpreted?

Can one perhaps say, they don't really any longer need to be understood?-If that means that they don't have to be further interpreted, that goes for words too; if it means, they cannot be further interpreted, then it's false. (Think of the explanation of gestures by words and vice versa). (PG, 48)

The first question posed here is whether ostensive definition further needs to be understood. Particularly in this context, this question is divided into the following two specific questions. First, is it true that ostensive definition no longer needs to be further interpreted? Wittgenstein's answer to the question is that ostensive definition need not be further interpreted once the interpretation is determined, and this is also the case for the translation of words into words in another language. Second, is it the case that ostensive definition cannot be interpreted differently? Wittgenstein's answer to the second question is that ostensive definition allows for multiple interpretations, that is, they can be subject to multiple interpretations. Given characteristic (2.1.3) of ostensive definition, that is, that ostensive definition does not allow for multiple interpretations, we see here that Wittgenstein is sceptical of this characteristic.

What are the reasons for his questions about the characteristic of ostensive definition? In order to follow Wittgenstein's thought process, let me introduce one of Wittgenstein's thought experiments related to the problem above. I reconstruct the argument in three steps. First, suppose that we give names to shades of colours in a chart.

Suppose that I lay down a method of designation. Suppose, for example, that I want to give names to shades of colours for my private use. I may do so by means of a chart; and of course I won't write a name beside a wrong colour (beside a colour I don't want to give that name

\footnotetext{
${ }^{7}$ Wittgenstein considers in detail the problem of ostensive definition or explanation in the period of PG and TS213: 'So what effect does an ostensive explanation have? Is it automatic, so to speak? That is to say, is it needed over and over, or is its effect like, say, an inoculation that changes us once and for all, or at least for the time being? ...How does the ostensive explanation "That is "red" help us to understand the word?' (TS213, 176)
} 
to). But why not? Why shouldn't 'red' go beside the green label and 'green' beside the red, etc.? If the ostensive definition merely replaces one sign by another, that shouldn't make any difference. (PG, 48) (cf. TS213, 49; 52)

$$
\begin{aligned}
& \text { 'red' } \square \text { red label } \\
& \text { 'green' } \square \text { green label }
\end{aligned}
$$

Wittgenstein states that ostensive gestures, such as pointing, attach colour names to the labels that are pointed to, and the way to arrange words and labels in the chart should not make any difference, because ostensive definition merely replaces one sign by another. The following is a thought experiment of a change in the arrangement:

Here there are at any rate two different possibilities. It may be that the table with green beside 'red' is used in such a way that a man who 'looks it up' goes diagonally from the word 'red' to the red label, and from the word 'green' to the green one and so on. We would then say that though the table was arranged differently (had a different spatial scheme) it connected the signs in the same way as the usual one. (PG, 48)

In this case, the table is arranged differently from the table in the previous example, and a man who refers to the table by ostensive definition goes diagonally from the word 'red' to the red label, and goes from the word 'green' to the green label. The man interprets the pointing in the same way as we do, however. In other words, based on the same interpretation of ostensive definition as ours, the man connects the words 'red' and 'green' with a red label and a green label, respectively. However, Wittgenstein goes on to show a second possibility:

It might also be that the person using the table looks from one side horizontally to another, and in some sentences uses a green label instead of the word 'red', and yet obeys an order like 'give me a red book' not by bringing a green book, but perfectly correctly by bringing a red one (i.e., one that we too would call 'red'). Such a man would have used the table in a different way from the first, but still in such a way that the word 'red' means the same colour for him as it does for us. Now it is the second case that interests us, and the question is: can a green label be a sample of red? (PG, 48)

$$
\begin{array}{ll}
\text { 'red' } & \square \text { green label } \\
\text { 'green' } & \square \text { red label }
\end{array}
$$


In this example, by ostensive definition, the man with his eyes moving horizontally from words and labels uses a green label for the word 'red'. The man apparently connects the word 'red' with the green label. Nevertheless, in applying the word 'red', for example, he brings us a red book or such a book as we call a 'red book' in response to the instruction 'Give me a red book'.

In this case, there are two explanations with regard to the man's attitude. First, by interpreting ostensive definition in the same way as we do, he connects a word 'red' with a green label and a word 'green' with a red label. However, in the stage of application of language, he makes a mistake when applying words to things, and, as a result, brings us a book as we call 'red' in response to the instruction 'Give me a red book'. Second, the man interpreted ostensive definition differently from the way we do and correctly applies, words to things in line with his own interpretation. For example, the man uses a green label in place of the word 'red', but on the basis of his unique interpretation of ostensive definition, in the stage of application, he ends up bringing us such a book as we call 'red' in response to the instruction 'Give me a red book'.

It is likely that solutions can be found on a case-by-case basis, but what is crucial now is the implication of this thought experiment to the current problem of why Wittgenstein is sceptical of characteristic (2.1.3). If, according to characteristic (2.1.3), ostensive definition does not allow for multiple interpretations, the second explanation must be incorrect because the truth of the second explanation implies that there can be different interpretations of ostensive definition. The problem is whether there is a solid reason which supports characteristic (2.1.3), that is, a reason why ostensive definition does not allow for multiple interpretations, and the second explanation can therefore be rejected. However, there seems no determinate reason supporting characteristic (2.1.3) other than the mere assumption of opponents of Wittgenstein. If there is no solid reason, there is no reason to exclude the possibility that ostensive definition can be subject to multiple interpretations, including misinterpretation.

For this reason, Wittgenstein questioned characteristic (2.1.3) of ostensive definition. Where, then, are components of ostensive definition, such as ostensive gestures or things that are pointed to, located in language learning? For the present, let us focus only on a role of ostensive gestures. Wittgenstein thinks that ostensive gestures are signs as a part of language in a sense. This is expressed as, 'The assignment of name to objects is nothing other than that produced by the words 'That is...' or by a table, etc. It is a part of the symbolism' (TS213, 173).

The arguments lead one to suspect characteristic (2.1.2) of ostensive definition, that is, that ostensive definition that supposedly connects words with things is detached from applications of language. Wittgenstein claims that 'language remains self-contained and autonomous' (PG, 97). ${ }^{8}$ In this view, ostensive gestures are one form of gestures in applications of language that

\footnotetext{
${ }^{8}$ With regard to this view on language, Glock notes, 'Wittgenstein does not deny that we, for the most part, talk about language-independent things; he denies only that the latter [ostensive definition] constitutes meaning of our words, and hence that there are semantic connections between language and world' (Glock, 1996, p. 275, emphasis original, square bracket added). In section three,
} 
need to be understood (PG, 44; TS213, 44). In other words, ostensive definition, encompassing such gestures, is a sign of understanding of words only if it is presupposed that the meaning of the sign is already known (TS213, 47).

Later, Wittgenstein argues that ostensive definition is a form of language game (PI, 27), because it involves employing words, such as demonstratives like 'this' as well as ostensive gestures, and, in order for this language game to make sense, the use of these words and actions must be understood in advance (PI, 31). ${ }^{9}$

Remember that, in section 2.1., the ostensive definition was a part of grammar and was regarded as a preparation for any application of language (TS213, 42; 43), distinct from applications of language. However, from the consideration above, it can be reasonably thought that these features of ostensive definition are not the case. In reality, this idea of grammar as a distinct preparatory stage for various applications of language, such as ordering, is doubted:

One thinks that learning language consists in giving names to objects ... To repeat-naming is something like attaching a label to a thing. One can say that this is preparatory to the use of a word. But what is it a preparation for? (PI, 26)

Instead of a preparation for the applications of language, ostensive definition or explanation has a distinct role as one of the language games, that is, a language game of asking and answering names of things based on prior understanding of demonstratives and ostensive gestures. Hence, as Williams concludes, 'If ostension plays a role in the initial acquisition of a first language, it cannot be that of ostensive definition' (Williams, 2010, p. 79).

\section{Roles of Training in Ostensive Teaching}

\subsection{Ostensive Teaching is Training}

Even after accepting the criticism of the characteristics of ostensive definition as a primary sign, we may reasonably think that there is some relationship between words and things. Wittgenstein presents an account of language games and describes the relationship between words and things in them. In this section, I focus on the features of ostensive teaching as education in the language games (BB, 77; PI, 6), particularly the role of pointing in ostensive teaching and the description of teaching practices with no distinct stages between grammar and applications of language.

Let us first outline the idea of ostensive teaching:

I focus on the relationship between language and world, or reality in language games in greater detail.

${ }^{9}$ Williams discusses in detail the idea that, in order to employ ostensive definition, expressions, such as 'this', must be explained in advance, and calls the problem the 'explanatory regress' (Williams, 1999, p. 191; 2010, p. 78). 
A child uses such primitive forms of language when he or she learns to talk. Here the teaching of language is not explanation, but training. (PI, 5)

An important part of the training will consist in the teacher's pointing to the objects, directing the child's attention to them, and at the same time uttering a word; for instance, the word 'slab' as he points to that shape. (I do not want to call this 'ostensive definition', because the child cannot as yet ask what the name is. I will call it 'ostensive teaching of words'. - I say that it will form an important part of the training, because it is so with human beings; not because it could not be imagined otherwise.) (PI, 6)

Ostensive teaching is supposed to be an important part of training, not explanation, so that children can acquire primitive forms of language, such as the teacher uttering the word 'red' while pointing to a red book.

However, the difference between ostensive teaching and ostensive definition is not clear, because even in ostensive teaching a teacher points to the objects. The difference is, it is thought, that ostensive teaching is a part of training. Thus, before addressing the problem of pointing in ostensive teaching, I clarify why ostensive teaching is a part of training.

There are two reasons why ostensive teaching is a part of training, based on two distinct roles of training. First, training enables language learners to learn to react to words in the same way as teachers do. Wittgenstein frequently mentions this type of training in the argument with regard to rule following:

Let me ask this: what has the expression of a rule-say a signpost-got to do with my action? What sort of connection is there here? -Well, perhaps this one: I have been trained to react to this sign in a particular way, and now I do so react to it. (PI, 198)

Wittgenstein considers the relationship between a signpost, such as ' $\rightarrow$ ', and our behaviour in going right. The signpost can be subject to multiple interpretations other than to make me turn right. However, on seeing the signpost on a street, I will turn right without hesitation. Wittgenstein calls such behaviour 'reaction'. The point of Wittgenstein's argument is that we act in a uniform way not because we first interpret signs unambiguously and follow the interpretation but because we follow the signs without interpreting them, that is, 'blindly' (PI, 219). Here, with respect to the meaning of the important, albeit vague, term 'blindly', let me refer to Fogelin (1995). ${ }^{10}$ Fogelin states, 'The metaphor of acting blindly is, to my mind, an inelegant way of pointing to the fact that when we follow a rule-as opposed to interpreting a rule-our actions come without reflection, as a matter of course' (pp. 158-9). Thus, based on

${ }^{10}$ In other part, Wittgenstein states that "what happens is not that this symbol cannot be further interpreted, but: I do no interpreting. I do not interpret, because I feel at home in the present picture' $(Z, 234)$. But this still seems ambiguous with respect to what Wittgenstein means by arguing for 'no interpreting' thesis. 
this Fogelin's interpretation, I call the training here the 'training of reaction'.

Analogously, in ostensive teaching as the training of reaction, language learners are trained to react to words in the same way as teachers do, without any interpretation of written or oral signs, for example, when they bring a red book in response to the instruction, 'Give me a red book'. ${ }^{11}$ In addition, pointing is not regarded as a sign of interpretation but as a sign to which we react in ostensive teaching, which is different from the role of pointing in ostensive definition.

Second, training teaches language learners to react in a uniform manner repetitively, so that expressions such as 'and so on' make sense to them.

In the course of this instruction, I shall show him the same colours, the same lengths, the same shapes, I shall make him find them and produce them, and so on. I shall, for instance, get him to continue an ornament pattern uniformly when told to do so.-And also to continue progressions. And so, for example, when given: ... ... to go on: ....... ....... (PI, 208)

In this example, instruction is designed for us to continue to apply repetitively beyond the given examples. ${ }^{12}$ For those who can do this, such expressions as 'continue it in the same way' or 'and so on' make sense (RFM, VI, 45). Let me call this instruction the 'training of repetition' because, in this instruction, we learn an 'endless' technique, that is, a technique to continue to apply in future cases (REM, V, 21). ${ }^{13}$ The training of repetition allows learners to continue to react in future applications beyond the cases given.

Given the above characteristic of training, training on repetition in ostensive teaching makes language learners react to words beyond the cases given. ${ }^{14}$ As Wittgenstein puts it, 'Teaching which is not meant to apply to anything but the examples given is different from that which 'points beyond' them' (PI, 208 emphasis original). Unlike the case of ostensive definition in section two, there is no stage of grammar where the connection between words and things is made, distinct from applications of language. Instead, children are thrown into the language

${ }^{11}$ In the consideration of mathematics, Wittgenstein says this about training and uniform activity: 'I can train someone in a uniform activity. E.g. in drawing a line like this with a pencil on paper: Now I ask myself, what is it that I want him to do, then? And what do I really mean by: he is always to go on in that way? The best answer to this that I can give myself, is an example like the one I have just given.' (RFM, VI, 17)

12 Wittgenstein considers the instruction in calculation in the philosophy of mathematics. Wittgenstein states, "Instruction in acting according to the rule can be described without employing "and so on." ... The effect of "and so on" will be to produce agreement going beyond what is done in the lessons, with the result that we all or nearly all count the same and calculate the same' (RFM, VI, 45).

${ }^{13}$ See Stickney (2008) and Williams (1999, Chapter 7) for the more detailed clarification of the relationship between mastering a technique and training.

${ }^{14}$ Cavell (1999, pp. 180-90) clarifies the significance of 'appropriate projections into future contexts' in the learning of ordinary language in comparison with the discussion in traditional philosophy. 
game of teaching practices so that they will be able to react to words in future applications, in other words, they will become master of language in the game. ${ }^{15}$

In summary, training plays at least the following two roles in ostensive teaching:

(3.1.1) The training of reaction enables language learners to learn to react to words in the same way as teachers do.

(3.1.2) The training of repetition makes language learners react to words beyond the cases given.

The reason ostensive teaching is not an explanation but is training is that ostensive teaching has these two types of training, the training of reaction and the training of repetition. Hence, 'If someone is not a master of a language, I may bring him to a mastery of it by training' (RFM, VI, 31).

\subsection{Things as Samples in Children's Initial Form of Languages}

Given that ostensive teaching has the characteristics (3.1.1) and (3.1.2), let us consider what precisely it means to say that things are samples in ostensive teaching. For example, suppose that a teacher points to various leaves while uttering the sound 'green' or orders language learners to bring samples of green objects (cf. PI, 50). The purpose of this teaching is to make learners acquire a technique to react uniformly and repetitively. For instance, by being trained, children learn to bring green things in response to the word 'green'. In the course of such training, ostensive teaching establishes an association between the word and the thing (PI, $6)^{16}$

During the process of training in language, learners are also learning to see things as certain kinds of samples, such as seeing leaves not as samples of shapes but as that of colours (cf. PI, $73 ; 74) .{ }^{17}$ In the preceding example, leaves or things that children bring by being told 'green' are not objects that are represented by words but 'means of representation' (PI, 50) in the sense that they have particular roles, such as samples of green colors, in the language game. In such language games, things that are pointed to by ostensive gestures are seen as a means of representation. This is precisely what it means to say that things are samples among the instruments of language in language acquisition. ${ }^{18}$

${ }^{15}$ From this consideration, although there are only language games, encompassing ostensive teaching, there may well be a distinction between novice and master (cf. Williams, 2010, pp. 79-81). In the language game, learners may be treated as novices.

${ }^{16}$ It has been said that 'ostensive teaching produces a causal association in the normatively structured language games' (cf. Williams, 2010, p. 80). A further problem concerning ostensive teaching would be how to reconcile a kind of causality with normativity.

17 This description, including the word 'see as', might be relevant to the concept of 'aspect', particularly the concept of 'continuous seeing' of an aspect' (PI, XI). With regard to the concept of aspect, see Mulhall (1993) in detail.

${ }^{18}$ In the postscript, Noya (2006) expounds on the role that samples plays in language games more 
Let us finally clarify why things must be samples in children's primitive language in language acquisition. Suppose now that, in an ostensive teaching, children have not acquired the skill to react to the word 'green' repetitively yet. For example, by being told 'green', they randomly bring such a book as adults see as a 'red book' instead of such things as they call 'green', encompassing 'green' leaves. Given the previous argument, this means that for the children, the red book acts as a sample of 'green' and some green leaves do not act as samples of green. Children as learners of this particular language may start to employ their primitive use of the word 'green' normatively in accordance with particular rules by learning how things seen as 'green' function as samples of green in the language game.

Given the particular example above, it may well be generally said that the learners acquire their first language through ostensive teaching only if things act as particular means of representation in a particular language, including things that are pointed to. This is why things must be samples, that is, a part of primitive languages when children have learned to talk.

\section{Conclusion}

I have examined the roles of two language teaching practices, that is, ostensive definition and ostensive teaching, and explicated the difference between them in line with Wittgenstein's thoughts and reflections. Let me summarize three points of my arguments. First, in order for ostensive definition to make sense to children as a language teaching practice, they must have a prior understanding of demonstratives, such as 'this', as well as ostensive gestures. Second, the training of reaction enables children to learn to react to words without reflection in the same way as adults do. In addition, the training of repetition allows children to apply words to new things. Finally, ostensive teaching based on these kinds of training enables children to react to words and ostensive gestures unreflectively and to treat new things of the same sort as samples shown in educational practices. I have proven that, in this sense, training has a significant role in educational practices.

My argument opens up further research to reconsider how training can be significant in educational practices, including training and drills in the classroom. For example, ostensive teaching as clarified could be seen as the foundation of reflective cognitive activities for small children, such as creative language activities. Moreover, considering that some psychologists and linguists, such as Bloom (2001) and Tomasello (1999; 2008), are beginning to examine ostensive gestures, my clarification concerning the roles of training will shed light on the problem of how small children understand both words and ostensive gestures.

\section{Acknowledgements}

Comments and suggestions by anonymous reviewers were illuminating. This work was supported by Fulbright grants.

concretely. Noya observes that, 'What is essential is that samples are among the instruments of language. Presenting a pale blue chip as a sample is not just to show the fact that a chip's colour is pale blue but to treat all other chips as the color like this, although they are not the same colour in the rigid sense' (Noya, 2006, p. 374). 


\section{References}

Baker, G. P., \& Hacker, P. M. S. (2009a). Wittgenstein: Understanding and meaning: Volume 1 of an analytical commentary on the philosophical investigations, part I: Essays and exegesis $\S \S 1-184$ (2nd ed. Rev. ed.). Malden, MA.; Oxford: Wiley-Blackwell.

Baker, G. P., \& Hacker, P. M. S. (2009b). Wittgenstein: Rules, grammar, and necessity: Volume 2 of an analytical commentary on the philosophical investigations, essays and exegesis of $\S \S 185-242$ (2nd ed.). Malden, MA.: Wiley-Blackwell.

Bloom, P. (2001). Précis of how children learn the meanings of words. Behavioral and Brain Sciences, 24, 1095-1103. Retrieved from http://groups.psych.northwestern.edu/waxman/ wordextension_CommPBloom.pdf

Burbules, N. C., \& Peters, M. (2001). Wittgenstein. In J. A. Palmer (Ed.), Fifty modern thinkers on education: From Piaget to the present (pp. 15-23). London; New York: Routledge.

Cavell, S. (1999). The claim of reason: Wittgenstein, skepticism, morality, and tragedy (2nd ed.). New York: Oxford University Press.

Fogelin, R. J. (1995). Wittgenstein: The arguments of the philosophers (2nd ed.). London: Routledge.

Glock, H. (1996). A Wittgenstein dictionary. Oxford: Blackwell.

Harris, J. F. (2002). Language, language games and ostensive definition. In S. Shanker, \& D. Kilfoyle (Eds.), Ludwig Wittgenstein: Critical assessments of leading philosophers, second series: Vol. 2 (pp. 126-33). London: Routledge.

Ishiguro, H. (2001). The so-called picture theory: Language and the world in Tractatus Logico-Philophicus. In H. Glock (Ed.), Wittgenstein: A critical reader (pp. 26-46). Malden; Massachusetts: Blackwell.

Luntley, M. (2007). Learning, empowerment, and judgement. Educational Philosophy and Theory, 39(4), 418-31. http://dx.doi.org/10.1111/j.1469-5812.2007.00348.x

Luntley, M. (2008). Training and learning. Educational Philosophy and Theory, 40(5), 695-711. http://dx.doi.org/10.1111/j.1469-5812.2008.00463.x

Mulhall, S. (1993). On being in the world: Wittgenstein and Heidegger on seeing aspects. London: Routledge.

Noya, S. (2006). 'Ronritetsugakuronkou' o yomu (Philosophizing with Wittgenstein through 'Tractatus Logico-Philosophicus'). Tokyo: Chikuma Shobo.

Stickney, J. (2008). Training and mastery of techniques in Wittgenstein's later philosophy: A response to Michael Luntley. Educational Philosophy and Theory, 40(5), 678-94. http://dx.doi.org/10.1111/j.1469-5812.2008.00418.x

Tomasello, M. (1999). The cultural origin of human cognition. Cambridge, Mass: Harvard 
University Press.

Tomasello, M. (2008). Origins of human cognition. Cambridge, Mass; London: MIT Press.

Williams, M. (1999). Wittgenstein, mind and meaning: Toward a social conception of mind. London; New York: Routledge.

Williams, M. (2010). Blind obedience: Paradox and learning in the later Wittgenstein. Abington: Routledge.

Wittgenstein, L. (1958). The blue and brown books. Oxford: Blackwell.

Wittgenstein, L. (1967). Zettle. Berkeley; Los Angeles; Oxford: Blackwell.

Wittgenstein, L. (1974). Philosophical grammar. Oxford: Blackwell.

Wittgenstein, L. (1978). Remarks on the foundations of mathematics (3rd ed.). Oxford: Blackwell.

Wittgenstein, L. (2001). Philosophical investigations (3rd ed.). Oxford: Blackwell.

Wittgenstein, L. (2007). The big type script TS213. Oxford: Blackwell.

\section{Copyright Disclaimer}

Copyright reserved by the author(s).

This article is an open-access article distributed under the terms and conditions of the Creative Commons Attribution license (http://creativecommons.org/licenses/by/3.0/). 